\title{
The Rubisco small subunits in the green algal genus Chloromonas provide insights into evolutionary loss of the eukaryotic
} carbon-concentrating organelle, the pyrenoid

\author{
Ryo Matsuzaki ${ }^{1,2}$, Shigekatsu Suzuki ${ }^{1}$, Haruyo Yamaguchi ${ }^{1}$, Masanobu Kawachi ${ }^{1}$, Yu Kanesaki ${ }^{3,4}$, \\ Hirofumi Yoshikawa ${ }^{5}$, Toshiyuki Mori ${ }^{6}$ and Hisayoshi Nozaki ${ }^{*}$ (1)
}

\begin{abstract}
Background: Pyrenoids are protein microcompartments composed mainly of Rubisco that are localized in the chloroplasts of many photosynthetic organisms. Pyrenoids contribute to the $\mathrm{CO}_{2}$-concentrating mechanism. This organelle has been lost many times during algal/plant evolution, including with the origin of land plants. The molecular basis of the evolutionary loss of pyrenoids is a major topic in evolutionary biology. Recently, it was hypothesized that pyrenoid formation is controlled by the hydrophobicity of the two helices on the surface of the Rubisco small subunit (RBCS), but the relationship between hydrophobicity and pyrenoid loss during the evolution of closely related algal/ plant lineages has not been examined. Here, we focused on, the Reticulata group of the unicellular green algal genus Chloromonas, within which pyrenoids are present in some species, although they are absent in the closely related species.
\end{abstract}

Results: Based on de novo transcriptome analysis and Sanger sequencing of cloned reverse transcription-polymerase chain reaction products, rbcS sequences were determined from 11 strains of two pyrenoid-lacking and three pyrenoid-containing species of the Reticulata group. We found that the hydrophobicity of the RBCS helices was roughly correlated with the presence or absence of pyrenoids within the Reticulata group and that a decrease in the hydrophobicity of the RBCS helices may have primarily caused pyrenoid loss during the evolution of this group.

Conclusions: Although we suggest that the observed correlation may only exist for the Reticulata group, this is still an interesting study that provides novel insight into a potential mechanism determining initial evolutionary steps of gain and loss of the pyrenoid.

Keywords: Chloromonas, Evolution, Green algae, Hydrophobicity of RBCS helices, Pyrenoid, Pyrenoid loss, Rubisco small subunit (RBCS)

\section{Background}

A pyrenoid is a protein body that is often surrounded by a starch sheath and is located in the chloroplast stroma

\footnotetext{
*Correspondence: nozaki@bs.s.u-tokyo.ac.jp

${ }^{7}$ Department of Biological Sciences, Graduate School of Science, The University of Tokyo, 7-3-1 Hongo, Bunkyo-ku, Tokyo 113-0033, Japan Full list of author information is available at the end of the article
}

of most eukaryotic algae and some hornwort species. The pyrenoid contributes to the $\mathrm{CO}_{2}$-concentrating mechanism [1-4]. This organelle consists mainly of ribulose-1,5-bisphosphate carboxylase/oxygenase (Rubisco), a key photosynthetic enzyme composed of eight large and eight small subunits [5]. Molecular phylogenetic analyses have suggested that the pyrenoid has 
been lost many times independently during the evolution of photosynthetic organisms [4, 6, 7], including during the origin of land plants [7]. Although recent papers have demonstrated that some Rubisco-binding proteins directly regulate pyrenoid morphology $[8,9]$, the molecular basis of the evolutionary loss of pyrenoids is largely unknown.

Based on transformational experiments of the unicellular pyrenoid-containing green alga Chlamydomonas reinhardtii, Meyer et al. found that absence of two $C$. reinhardtii helices of the Rubisco small subunit (RBCS) results in no pyrenoid formation even though the spinach RBCS helices are present in the Rubisco [10]. They suggested that hydrophobic interactions between Rubisco molecules within the pyrenoid via two helices on the surface of RBCS are correlated with pyrenoid formation [10]. A substantial amount of work has subsequently highlighted that the interaction of the linker protein "Essential Pyrenoid Component 1 (EPYC1)" with RBCS, specifically the two helices, is critical for pyrenoid formation $[8,11,12]$. Recently, Goudet et al. [13] examined RBCS sequences across chlorophyte and streptophyte green algae and concluded that specific residues in the RBCS helices [10] were not sufficient to explain the pyrenoid occurrence across the entire green algal phylum. However, the relationship between the hydrophobicity of the two RBCS helices and presence or absence of pyrenoids within a closely related lineage has not been studied.

The unicellular green algal genus Chloromonas belongs to Chloromonadinia, a strongly supported primary clade [14] in the order Chlamydomonadales (=Volvocales), and includes both pyrenoid-containing and -lacking species $[6,15,16]$. Within this genus, the Reticulata group is a small clade that includes at least three pyrenoid-containing species and two pyrenoidlacking species; based on the phylogenetic tree constructed and distribution of presence or absence of pyrenoids in operational taxonomic units, it has been suggested that pyrenoids have been lost twice during the evolution of this group [17]. The $\mathrm{CO}_{2}$-concentrating mechanism, chloroplast ultrastructure, and Rubisco distribution in the chloroplast have been studied extensively in several strains and species belonging to the Reticulata group $[6,18]$. Many amino acid substitutions were found in the Rubisco large subunit (RBCL) in the Reticulata group or the genus Chloromonas and a possible relationship between RBCL substitutions and loss of pyrenoids was suggested [15]. However, the nuclear $r b c S$ genes in this group have not been studied.

Here, we determined the $r b c S$ sequences of 11 strains of five species in the Reticulata group [17] using de novo transcriptome analysis and Sanger sequencing of cloned reverse transcription-polymerase chain reaction (RT-PCR) products. We found that the hydrophobicity of the RBCS helices was correlated with the presence or absence of the pyrenoid within the Reticulata group.

\section{Results \\ Phylogeny of 11 Chloromonas strains of the Reticulata group}

The sister relationship between $C$. chlorococcoides and $C$. reticulata was more robustly resolved [with 1.00 posterior probability in Bayesian inference (BI) and $96-100 \%$ bootstrap values [19] in three other phylogenetic methods] than in the previous study [17] (Fig. 1). Although the bootstrap value by maximum likelihood (ML) method was low (52\%), C. rosae was sister to the clade composed of $C$. chlorococcoides and C. reticulata [with 0.99 posterior probability in BI and $83-98 \%$ bootstrap values in maximum parsimony (MP) and neighbor-joining (NJ) methods]. It was suggested that pyrenoids have been lost twice during the evolution of this group (Fig. 1).

Obvious contradictions of the single markers in phylogenetic positions of C. rosae, C. difformis and C. typhlos were recognized, but only supported with low statistical supports in $28 \mathrm{~S}$ ribosomal DNA- and P700 chlorophyll $a$-apoprotein A1 gene ( $p s a A$ )-based trees (Additional file 1: Fig. S1). Only ML analysis (with 58\% bootstrap value) resolved sister relationship between $C$. difformis and $C$. typhlos in the $28 \mathrm{~S}$ ribosomal DNA tree. The psaA tree suggested sister relationship between $C$. difformis and the other four Chloromonas species with 0.95 posterior probability in Bayesian inference and $57 \%$ bootstrap value in NJ method (Additional file 1: Fig. S1). In contrast, the phylogenetic positions of $C$. rosae, C. difformis and C. typhlos supported with high bootstrap values (8398\%) in NJ and MP analyses of the concatenated data set (Fig. 1) were also resolved in the ITS-2 tree with 90-96\% bootstrap values in NJ and MP methods (Additional file 1: Fig. S1). In addition, the previous phylogenetic analysis based on the combined data set lacking ITS-2 sequences resolves the most basal position of $C$. typhlos with $51-71 \%$ bootstrap values in ML, NJ and MP calculations, but does not demonstrate $50 \%$ or more bootstrap values or 0.95 or more posterior probability in the four phylogenetic methods for supporting the sister relationship between $C$. rosae and C. difformis shown in the tree topology [17]. Thus, the ITS-2 sequence information is considered to contribute largely to the resolution of the basal phylogeny within the Reticulata group in the tree based on the present combined data set (Fig. 1). 


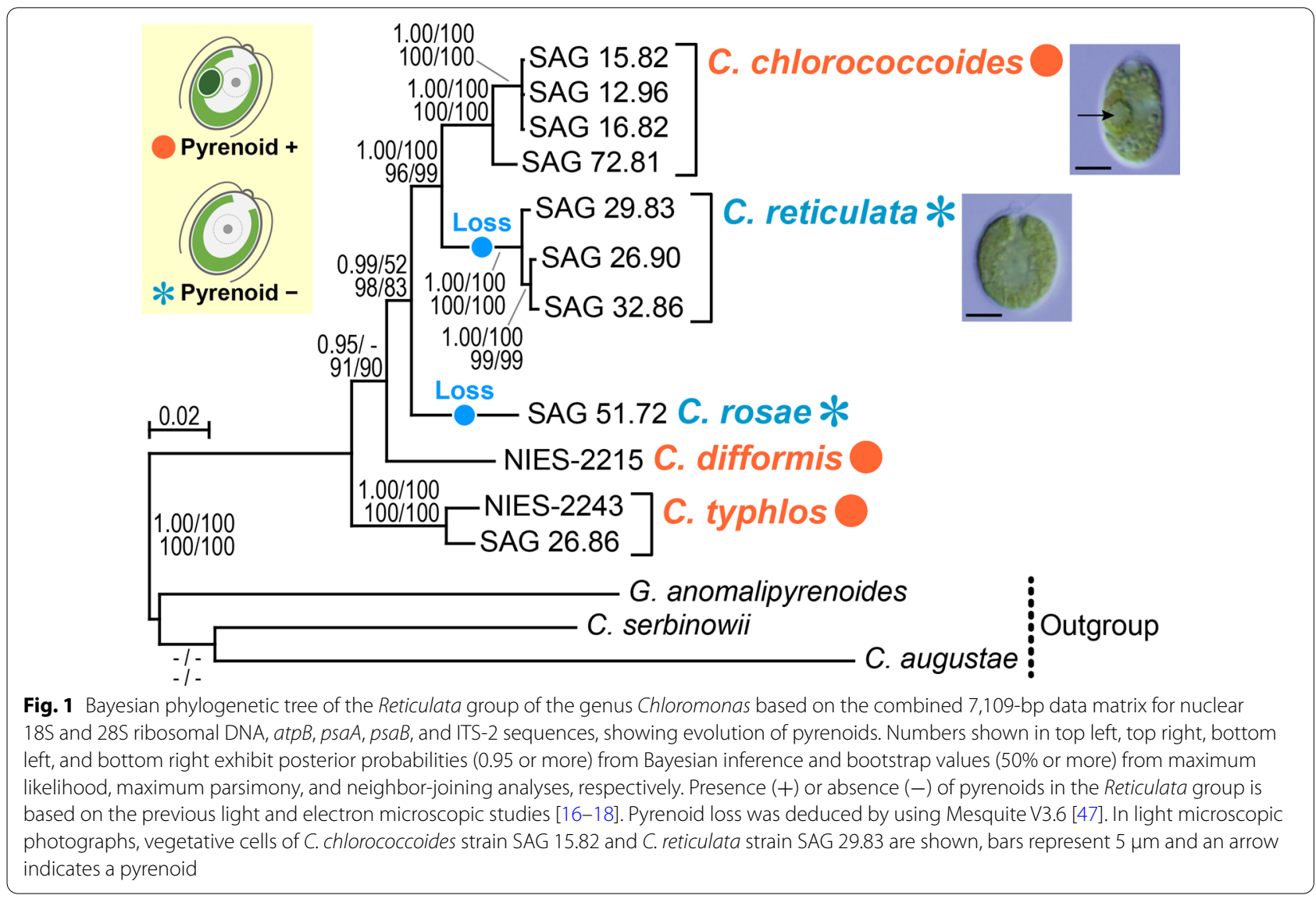

\section{Paralogs of $r b c S$ in the Reticulata group}

Multiple $r b c S$ sequences were detected in the de novo transcriptome assembly or cloned RT-PCR-products of all strains of the Reticulata group (Additional file 2: Table S1). In order to resolve the diversity and phylogeny of the $r b c S$ paralogs in the Reticulata group, phylogenetic analyses were carried out. The $r b c S$ phylogenetic tree did not resolve basal relationships of the genes in the Reticulata group (Fig. 2). However, six or three homologs from C. typhlos (two strains) or C. difformis (one strain), respectively, constituted a monophyletic group (Fig. 2). Three paralogs from a single strain (SAG 15.82) of C. chlorococcoides belonged to a clade composed of only strains of the same species. Six of 10 C. reticulata $r b c S$ sequences formed a clade which included three paralogs from a single strain (SAG 32.86). Therefore, the $r b c S$ genes might have been duplicated after the origin of each of the four Chloromonas species. Alternatively, gene conversion [20] could be considered to explain the apparent monophyly of the paralogs from the same species within the Reticulata group. Interestingly, two paralogs of C. rosae (one strain) were separated from each other, and each was sister to C. reticulata homolog(s) (Fig. 2). Because of presence of multiple $r b c S$ paralogs in all five species and the discrepancy in the phylogeny of $C$. rosae and $C$. reticulata between the $r b c S$ phylogeny and the previous species trees [16, 17], $r b c S$ sequences were not used in the present study for phylogeny of species within the Reticulata group (Fig. 1).

\section{Hydrophobicity of RBCS helices}

Table 1 shows the calculated hydrophobicity of RBCS helices A and B from the chlamydomonadalean species examined in this study. Figure 3 compares the hydrophobicity between pyrenoid-containing and -lacking species of Chlamydomonadales.

Within the Reticulata group, for all 20 RBCS sequences, the hydrophobicity of the RBCS helices from the pyrenoid-containing species was higher $(-19.6$ to -29.6$)$ than those of all 12 RBCS sequences from pyrenoidlacking species ( -30.5 to -33.6$)$ (Fig. 3) (Table 1). The Brunner-Munzel test detected a significant difference $(\mathrm{p}<0.001)$ between the pyrenoid-containing and -lacking species within the Reticulata group (Fig. 3). These results support previous studies that suggested that the 


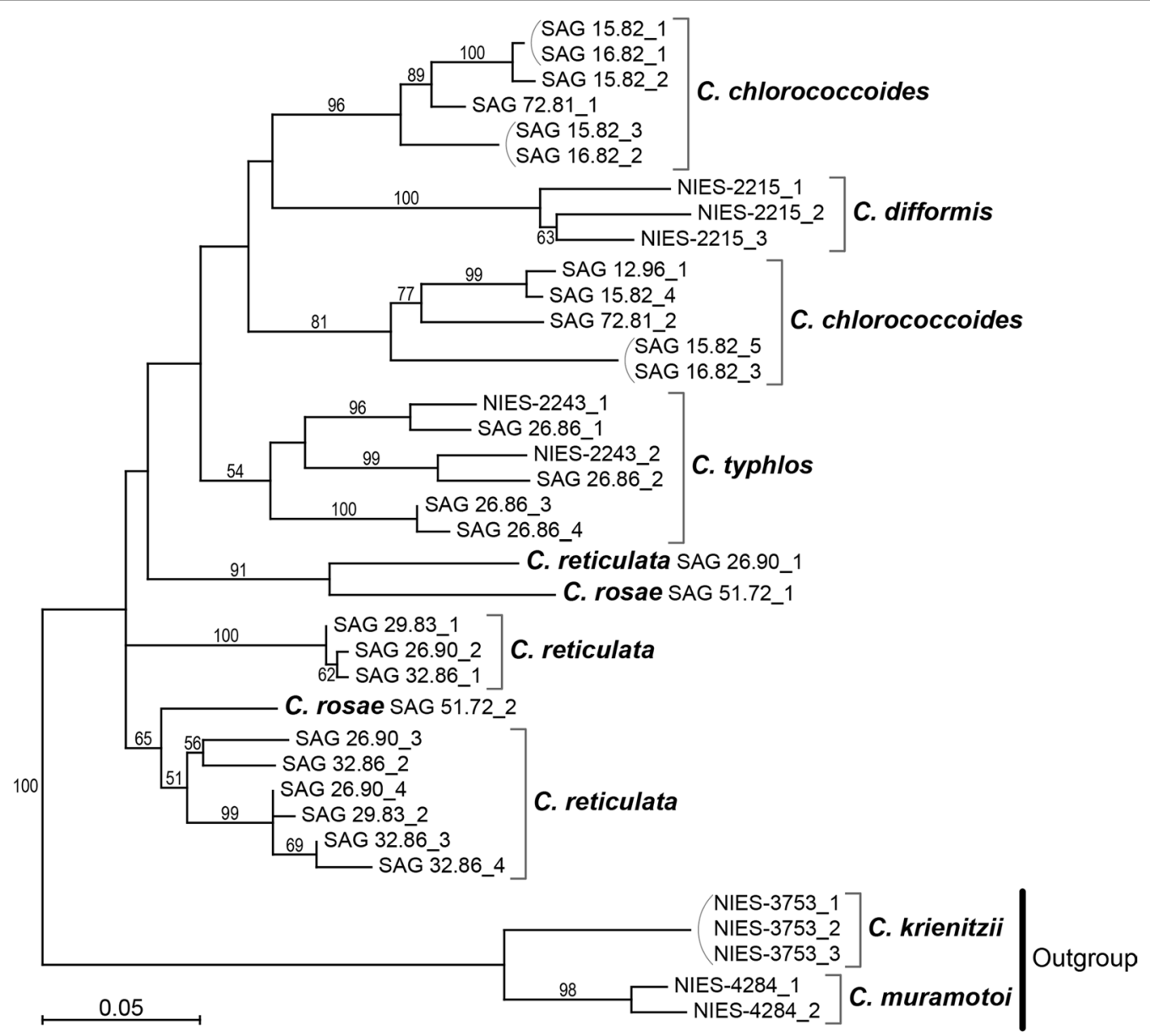

Fig. 2 Phylogenetic analysis of $r b c S$ sequences from the Reticulata group. The tree was constructed based on maximum likelihood method using 307 base pairs of coding regions of rbcS (Table 1). Numbers at the branches indicate bootstrap values (50\% or more). For details, see Methods of the main text

interaction between pyrenoid-component proteins contributes to pyrenoid formation [8-12].

To investigate the correlation between the presence/absence of pyrenoids and the hydrophobicity of the RBCS helices among various lineages within Chlamydomonadales, the hydrophobicity of the helices was examined in 12 other lineages in the following order: snow Chloromonas species in the strongly supported primary clade Chloromonadinia [14], followed by 10 other strongly supported primary clades: (Reinhardtinia, Oogamochlamydinia, Moewusinia, Phacotinia, Chlorogonia, Stephanosphaerinia, Dunaliellinia, Radicarteria, Hafniomonas, and Crucicarteria) and Spermatozopsis [14] (Table 1). Both snow Chloromonas species lack pyrenoids [21, 22]. Spermatozopsis lacks pyrenoids [23]; its phylogenetic position is uncertain [14, 24] although it may be sister to Radicarteria [14]. Hafniomonas and Crucicarteria are positioned near the base of Chlamydomonadales and have a pyrenoid [23-25]. Species from other strongly primary clades examined in the present study (Table 1) possess pyrenoids [22, 23].

Comparing the hydrophobicity of the RBCS helices from various lineages within Chlamydomonadales showed that the hydrophobicity of the RBCS helices does not necessarily correspond to the presence or absence of a pyrenoid (Fig. 3b). The RBCS helices of pyrenoid-lacking snow Chloromonas species had relatively high hydrophobicities, whereas the values for Phacotinia, Radicarteria, Hafniomonas and Crucicarteria with pyrenoids in the chloroplast were low (Fig. 3b). Very recently, other protein factors were reported to contribute to pyrenoid formation in the Chlamydomonas reinhardtii chloroplast $[8,9,11,12]$. Consequently, the hydrophobicity of the RBCS helices is not the only factor that controls pyrenoid formation. All snow species of Chloromonas lack pyrenoids and constitute a relatively large, pyrenoid-lacking lineage, the subclade 2 of clade A [26] or snow algae clade 
Table 1 List of species/strains of 12 lineages of the Chlamydomonadales [14] used for comparison of hydrophobicity scales of RBCS helices (Fig. 3)

\begin{tabular}{|c|c|c|c|c|c|c|}
\hline $\begin{array}{l}\text { Lineage or strongly } \\
\text { supported primary } \\
\text { clade [14] }\end{array}$ & Species & Strain & Sequence $^{a}$ & Source of $r b c S$ & $\begin{array}{l}\text { Accession number } \\
\text { of } r b c S\end{array}$ & Hydrophobicity ${ }^{\mathbf{b}}$ \\
\hline \multirow{20}{*}{$\begin{array}{l}\text { Chloromonadinia } \\
\text { (Reticulata group with } \\
\text { pyrenoid) }\end{array}$} & \multirow{11}{*}{$\begin{array}{l}\text { Chloromonas chlorococ- } \\
\text { coides }\end{array}$} & \multirow[t]{5}{*}{ SAG 15.82} & \multirow[t]{5}{*}{5} & \multirow[t]{5}{*}{$\mathrm{mRNA}^{\mathrm{c}}$} & LC547865 & -23.6 \\
\hline & & & & & LC547866 & -23.6 \\
\hline & & & & & LC547867 & -23.0 \\
\hline & & & & & LC547868 & -25.9 \\
\hline & & & & & LC547869 & -26.3 \\
\hline & & SAG 12.96 & 1 & $\mathrm{mRNA}^{\mathrm{c}}$ & LC547870 & -25.9 \\
\hline & & \multirow[t]{3}{*}{ SAG 16.82} & \multirow[t]{3}{*}{3} & \multirow[t]{3}{*}{$\mathrm{mRNA}^{\mathrm{c}}$} & LC547871 & -23.6 \\
\hline & & & & & LC547872 & -23.0 \\
\hline & & & & & LC547873 & -26.3 \\
\hline & & \multirow[t]{2}{*}{ SAG 72.81} & \multirow[t]{2}{*}{2} & \multirow[t]{2}{*}{$\mathrm{mRNA}^{\mathrm{c}}$} & LC547874 & -23.6 \\
\hline & & & & & LC547875 & -23.0 \\
\hline & \multirow[t]{3}{*}{ Chloromonas difformis } & \multirow[t]{3}{*}{ NIES-2215 } & \multirow[t]{3}{*}{3} & \multirow[t]{3}{*}{$\mathrm{mRNA}^{\mathrm{c}}$} & LC547876 & -26.6 \\
\hline & & & & & LC547877 & -29.6 \\
\hline & & & & & LC547878 & -26.6 \\
\hline & \multirow[t]{6}{*}{ Chloromonas typhlos } & \multirow[t]{2}{*}{ NIES-2243 } & \multirow[t]{2}{*}{2} & \multirow[t]{2}{*}{$\mathrm{mRNA}^{\mathrm{c}}$} & LC547879 & -22.8 \\
\hline & & & & & LC547880 & -24.3 \\
\hline & & \multirow[t]{4}{*}{ SAG 26.86} & \multirow[t]{4}{*}{4} & \multirow[t]{4}{*}{$\mathrm{mRNA}^{\mathrm{c}}$} & LC547881 & -22.8 \\
\hline & & & & & LC547882 & -19.6 \\
\hline & & & & & LC547883 & -27.7 \\
\hline & & & & & LC547884 & -27.7 \\
\hline Chloromonadinia (Reticu- & Chloromonas reticulata & SAG 29.83 & 2 & $\mathrm{mRNA}^{\mathrm{c}}$ & LC547885 & -30.5 \\
\hline lata group without & & & & & LC547886 & -31.2 \\
\hline & & SAG 26.90 & 4 & $m R N A^{c}$ & LC547887 & -31.6 \\
\hline & & & & & LC547888 & -30.5 \\
\hline & & & & & LC547889 & -30.5 \\
\hline & & & & & LC547890 & -31.2 \\
\hline & & SAG 32.86 & 4 & $\mathrm{mRNA}^{\mathrm{c}}$ & LC547891 & -30.5 \\
\hline & & & & & LC547892 & -30.5 \\
\hline & & & & & LC547893 & -31.2 \\
\hline & & & & & LC547894 & -31.2 \\
\hline & Chloromonas rosae & SAG 51.72 & 2 & $\mathrm{mRNA}^{\mathrm{c}}$ & LC547895 & -31.4 \\
\hline & & & & & LC547896 & -33.6 \\
\hline Chloromonadinia (snow & Chloromonas krienitzii & NIES-3753 & 3 & $\mathrm{mRNA}^{\mathrm{c}}$ & ICPW01000006 & -23.4 \\
\hline & & & & & ICPW01000007 & -23.4 \\
\hline & & & & & ICPW01000008 & -23.4 \\
\hline & Chloromonas muramotoi & NIES-4284 & 2 & $\mathrm{mRNA}^{\mathrm{c}}$ & ICPX01000119 & -15.7 \\
\hline & & & & & ICPX01000120 & -15.7 \\
\hline Crucicarteria & Carteria crucifera & SAG 8-7a & 1 & $m R N A^{d}$ & VIAU scaffold 2059943 & -25.6 \\
\hline & Carteria cerasiformis & NIES-424 & 2 & $\mathrm{mRNA}^{\mathrm{c}}$ & ICQZ01000174 & -34.5 \\
\hline & & & & & ICQZ01001652 & -30.6 \\
\hline & & NIES-425 & 1 & $\mathrm{mRNA}^{\mathrm{c}}$ & ICRA01000128 & -34.5 \\
\hline Chlorogonia & Haematococcus lacustris & NIES-144 & 4 & gDNA & BLLF01000007 & -24.2 \\
\hline & & & & & BLLF01000015 & -24.2 \\
\hline & & & & & BLLF01001246 & -24.2 \\
\hline & & & & & BLLF01002948 & -24.2 \\
\hline & & CCAC 0055 & 2 & $m R N A^{d}$ & AGIO scaffold 2001898 & -24.2 \\
\hline & & & & & ODXI scaffold 2002606 & -24.2 \\
\hline
\end{tabular}


Table 1 (continued)

\begin{tabular}{|c|c|c|c|c|c|c|}
\hline $\begin{array}{l}\text { Lineage or strongly } \\
\text { supported primary } \\
\text { clade [14] }\end{array}$ & Species & Strain & Sequence $^{a}$ & Source of $r b c S$ & $\begin{array}{l}\text { Accession number } \\
\text { of } r b c s\end{array}$ & Hydrophobicity ${ }^{\mathbf{b}}$ \\
\hline \multirow[t]{6}{*}{ Dunaliellinia } & Dunaliella parva & & 1 & mRNA & HQ315783 & -23.8 \\
\hline & Dunaliella salina & & 1 & mRNA & AY739272 & -24.4 \\
\hline & \multirow[t]{2}{*}{ Dunaliella tertiolecta } & & 1 & gDNA & AY530155 & -32.2 \\
\hline & & CCMP 364 & 1 & $m R N A^{d}$ & ZDIZ scaffold 2000214 & -32.2 \\
\hline & \multirow[t]{2}{*}{ Asteromonas gracilis } & \multirow[t]{2}{*}{ CCAC 0049} & \multirow[t]{2}{*}{2} & \multirow[t]{2}{*}{$m R N A^{d}$} & MNPL scaffold 2000234 & -13.6 \\
\hline & & & & & NTLE scaffold 2002920 & -13.6 \\
\hline Hafniomonas & Hafniomonas reticulata & CCAC 0530/1 & 1 & $m R N A^{d}$ & FXHG scaffold 2070561 & -37.2 \\
\hline \multirow[t]{8}{*}{ Moewusinia } & $\begin{array}{l}\text { Chlamydomonas moe- } \\
\text { wusii }\end{array}$ & & 1 & mRNA & X13974 & -29.7 \\
\hline & \multirow[t]{2}{*}{ Chlamydomonas bilatus } & \multirow[t]{2}{*}{ SAG 7.72} & \multirow[t]{2}{*}{2} & \multirow[t]{2}{*}{$\mathrm{mRNA}^{\mathrm{d}}$} & OVHR scaffold 3000834 & -25.3 \\
\hline & & & & & OVHR scaffold 3000835 & -25.3 \\
\hline & $\begin{array}{l}\text { Chlamydomonas eus- } \\
\text { tigma }\end{array}$ & NIES-2499 & 1 & gDNA & BEGY01000097 & -37.2 \\
\hline & Chlamydomonas sp. & HS-5 & 1 & mRNA & AU066498 & -20.1 \\
\hline & \multirow[t]{3}{*}{ Chlamydomonas sp. } & \multirow[t]{3}{*}{ W80 } & \multirow[t]{3}{*}{3} & \multirow[t]{3}{*}{ mRNA } & DC847488 & -20.1 \\
\hline & & & & & DC847494 & -20.1 \\
\hline & & & & & DC847626 & -19.1 \\
\hline \multirow[t]{2}{*}{ Oogamochlamydinia } & $\begin{array}{l}\text { Oogamochlamys } \\
\text { gigantea }\end{array}$ & SAG 44.91 & 1 & $m R N A^{d}$ & XDLL scaffold 2047213 & -18.1 \\
\hline & Lobochlamys segnis & SAG 50.84 & 1 & $m R N A^{d}$ & OFUE scaffold 2045013 & -18.1 \\
\hline Phacotinia & Phacotus lenticularis & SAG 61-1 & 1 & $m R N A^{d}$ & ZIVZ scaffold 2002271 & -34.9 \\
\hline \multirow[t]{3}{*}{ Radicarteria } & \multirow[t]{3}{*}{ Carteria obtusa } & \multirow[t]{3}{*}{ SAG 39.84} & \multirow[t]{3}{*}{3} & \multirow[t]{3}{*}{$\mathrm{mRNA}^{\mathrm{d}}$} & RUIF scaffold 2001762 & -29.6 \\
\hline & & & & & RUIF scaffold 2001763 & -32.4 \\
\hline & & & & & RUIF scaffold 2001764 & -32.4 \\
\hline \multirow[t]{15}{*}{ Reinhardtinia } & \multirow{2}{*}{$\begin{array}{l}\text { Chlamydomonas rein- } \\
\text { hardtii }\end{array}$} & \multirow[t]{2}{*}{ CC-503cw92mt+ } & \multirow[t]{2}{*}{2} & \multirow[t]{2}{*}{ mRNA } & XM_001702354 & -13.4 \\
\hline & & & & & XM_001702357 & -13.4 \\
\hline & \multirow[t]{2}{*}{$\begin{array}{l}\text { Chlamydomonas asym- } \\
\text { metrica }\end{array}$} & NIES-2207 & 2 & gDNA & $\begin{array}{l}\text { BDDA01000282 (2 } \\
\text { sequences) }\end{array}$ & -13.4 \\
\hline & & & & & & -13.4 \\
\hline & Chlamydomonas cribrum & SAG 13.72 & 1 & $m R N A^{d}$ & BCYF scaffold 2001609 & -14.0 \\
\hline & Chlamydomonas debary- & NIES-2212 & 3 & gDNA & BDDB01000073 & -14.0 \\
\hline & & & & & BDDB01000328 & -14.0 \\
\hline & & & & & BDDB01001769 & -14.0 \\
\hline & Chlamydomonas globosa & SAG 7.73 & 1 & mRNA & EC116339 & -13.4 \\
\hline & $\begin{array}{l}\text { Chlamydomonas } \\
\text { sphaeroides }\end{array}$ & NIES-2242 & 3 & gDNA & $\begin{array}{l}\text { BDDC01000297 (2 } \\
\text { seguences) }\end{array}$ & -14.0 \\
\hline & & & & & & -14.0 \\
\hline & & & & & BDDC01001831 & -13.4 \\
\hline & "Chloromonas" oogama & SAG 9.79 & 1 & $m R N A^{d}$ & IHOI scaffold 2001609 & -13.4 \\
\hline & Gonium pectorale & CCAC 0085 & 2 & $m R N A^{d}$ & KUJU scaffold 2000900 & -16.0 \\
\hline & & & & & KUJU scaffold 2000901 & -16.0 \\
\hline
\end{tabular}


Table 1 (continued)

\begin{tabular}{|c|c|c|c|c|c|c|}
\hline $\begin{array}{l}\text { Lineage or strongly } \\
\text { supported primary } \\
\text { clade [14] }\end{array}$ & Species & Strain & Sequence $^{a}$ & Source of $r b c S$ & $\begin{array}{l}\text { Accession number } \\
\text { of } r b c S\end{array}$ & Hydrophobicity ${ }^{\mathbf{b}}$ \\
\hline & \multirow[t]{3}{*}{ Eudorina elegans } & \multirow[t]{3}{*}{ CCAC 0011} & \multirow[t]{3}{*}{3} & \multirow[t]{3}{*}{ mRNA $^{d}$} & RNAT scaffold 2001381 & -16.0 \\
\hline & & & & & RNAT scaffold 2001382 & -16.0 \\
\hline & & & & & RNAT scaffold 2001383 & -16.0 \\
\hline & $\begin{array}{l}\text { Heterochlamydomonas } \\
\text { inaequalis }\end{array}$ & SAG 4.75 & 1 & $m R N A^{d}$ & IRYH scaffold 2037065 & -17.3 \\
\hline & \multirow[t]{3}{*}{ Lobomonas francei } & \multirow[t]{3}{*}{ SAG 45-1 } & \multirow[t]{3}{*}{3} & \multirow[t]{3}{*}{$\mathrm{mRNA}^{\mathrm{d}}$} & JKKI scaffold 2001057 & -15.4 \\
\hline & & & & & JKKI scaffold 2001059 & -15.4 \\
\hline & & & & & JKKI scaffold 2001061 & -15.7 \\
\hline & Neochlorosarcina sp. & CCAC 0208 & 1 & $m R N A^{d}$ & USIX scaffold 2005162 & -14.0 \\
\hline & \multirow[t]{7}{*}{ Volvox aureus } & \multirow[t]{3}{*}{ CCAC 1028} & \multirow[t]{3}{*}{3} & \multirow[t]{3}{*}{$m R N A^{d}$} & JWGT scaffold 2000603 & -13.4 \\
\hline & & & & & JWGT scaffold 2000604 & -13.4 \\
\hline & & & & & JWGT scaffold 2000606 & -13.4 \\
\hline & & \multirow[t]{4}{*}{ CCAC 2242} & \multirow[t]{4}{*}{4} & \multirow[t]{4}{*}{$m R N A^{d}$} & WRSL scaffold 2000117 & -13.4 \\
\hline & & & & & WRSL scaffold 2000118 & -13.4 \\
\hline & & & & & WRSL scaffold 2000119 & -13.4 \\
\hline & & & & & WRSL scaffold 2000120 & -13.4 \\
\hline & \multirow[t]{3}{*}{ Volvox carteri } & & \multirow[t]{3}{*}{3} & \multirow[t]{3}{*}{ gDNA } & \multirow[t]{3}{*}{ AY205158 (3 sequences) } & -13.4 \\
\hline & & & & & & -13.4 \\
\hline & & & & & & -13.4 \\
\hline & \multirow[t]{5}{*}{ Volvox globator } & \multirow[t]{5}{*}{ CCAC 2662} & \multirow[t]{5}{*}{5} & \multirow[t]{5}{*}{$m R N A^{d}$} & ASPU scaffold 2003346 & -13.4 \\
\hline & & & & & ASPU scaffold 2003347 & -13.4 \\
\hline & & & & & ASPU scaffold 2003348 & -13.4 \\
\hline & & & & & ASPU scaffold 2003349 & -13.4 \\
\hline & & & & & ASPU scaffold 2003350 & -13.4 \\
\hline Stephanosphaerinia & $\begin{array}{l}\text { Chlorococcum microstig- } \\
\text { matum }^{f}\end{array}$ & SAG 11-43 & 1 & $m R N A^{d}$ & QRTH scaffold 2038871 & -24.1 \\
\hline \multirow[t]{2}{*}{ Spermatozopsis ${ }^{9}$} & \multirow[t]{2}{*}{ Spermatozopsis similis } & \multirow[t]{2}{*}{ CCAC 0013} & \multirow[t]{2}{*}{2} & \multirow[t]{2}{*}{$\mathrm{mRNA}^{\mathrm{d}}$} & ENAU scaffold 2000800 & -28.8 \\
\hline & & & & & ENAU scaffold 2000801 & -28.8 \\
\hline
\end{tabular}

a Numbers of RBCS paralogs used for comparison of hydrophobicity scales of helices A and B (Fig. 3)

b Hydrophobicity of RBCS helices A and B. For details, see Methods

c For details, see Additional file 3: Table S2

d One thousand plant transcriptome data (https://db.cngb.org/onekp/) [48]

e Formerly identified as Chlamydomonas incerta [49]

${ }^{f}$ Formerly identified as Chloromonas perforata [50]

9 Not identified as strongly supported primary clade because of its uncertain phylogenetic position [14]

(SA clade) [21, 27], which is phylogenetically separated from the Reticulata group of Chloromonas. Thus, the common ancestral species of the extant snow Chloromonas species might have lacked pyrenoids in the chloroplast and diverged in the distant past; many changes in pyrenoid formation factors would have accumulated independently from the Reticulata group after divergence. Therefore, it is difficult to discuss pyrenoid presence/absence only in terms of the RBCS protein among the lineages within Chlamydomonadales. However, the evolutionary loss of pyrenoids within the Reticulata group is recognized as recent (Fig. 1), 


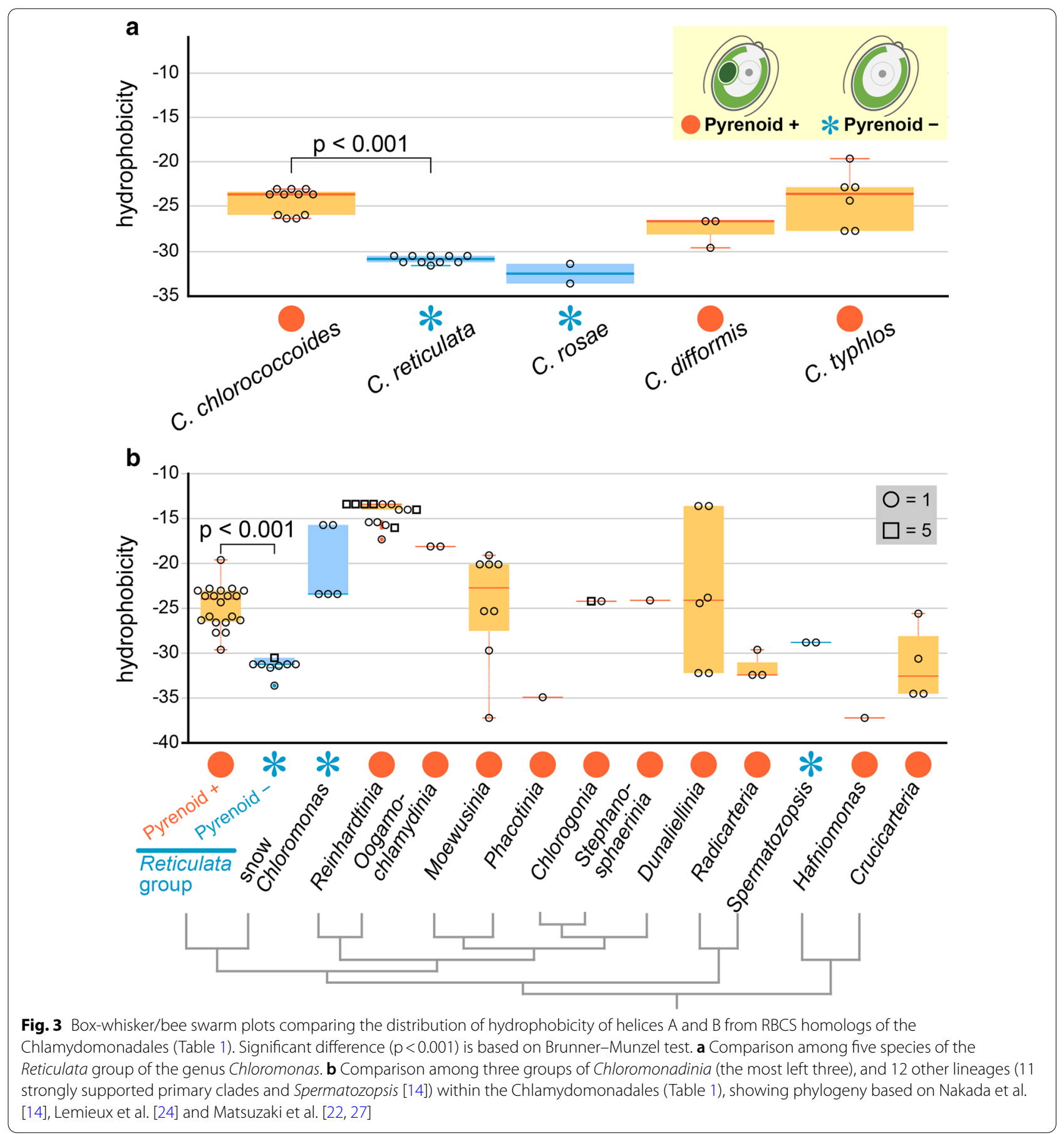

and the hydrophobicity of the RBCS helices differed significantly between pyrenoid-containing and -lacking species (Fig. 3). Therefore, during the initial stage of pyrenoid loss in the Reticulata group, changes in the hydrophobicity of the RBCS helices might have directly caused the disappearance of pyrenoids from the chloroplast.

\section{Comparison of sister species with and without pyrenoids}

As discussed above, various molecular factors can be considered regarding the accumulation of Rubisco proteins to form pyrenoids [8-12]. Thus, comparison between closely related species with and without pyrenoids should be helpful to resolve critical factor causing pyrenoid loss/gain during speciation between these two species. Among sister species of the Reticulata group, 
Chloromonas chlorococcoides has and C. reticulata does not have pyrenoids (Fig. 1). To investigate differences in the amino acid sequences of the RBCS helices that may cause the difference in pyrenoid formation between these two species, the RBCS helices from these two species were compared: 11 sequences from four strains of $C$. chlorococcoides and 10 sequences from three strains of $C$. reticulata (Fig. 4). Within the 21 amino acid positions of helices A and B that were used to calculate hydrophobicity, one position differed markedly in amino acid hydrophobicity between these two species: the first position of helix B, corresponding to the 131 amino acid position in RBCS from Chlamydomonas reinhardtii [28]. The amino acid at this position in all of the C. chlorococcoides RBCS sequences was alanine (amino acid hydrophobicity $=1.8$ [29]), while that in all of the C. reticulata RBCS sequences was proline (amino acid hydrophobicity $=-1.6$ [29]) (Fig. 4). Therefore, a mutation of this codon $(-3.4$ difference in amino acid hydrophobicity) might have significantly contributed to the loss of pyrenoids during the divergence of the ancestor of the pyrenoid-lacking species C. reticulata from a common ancestral species that may have possessed pyrenoids. However, we

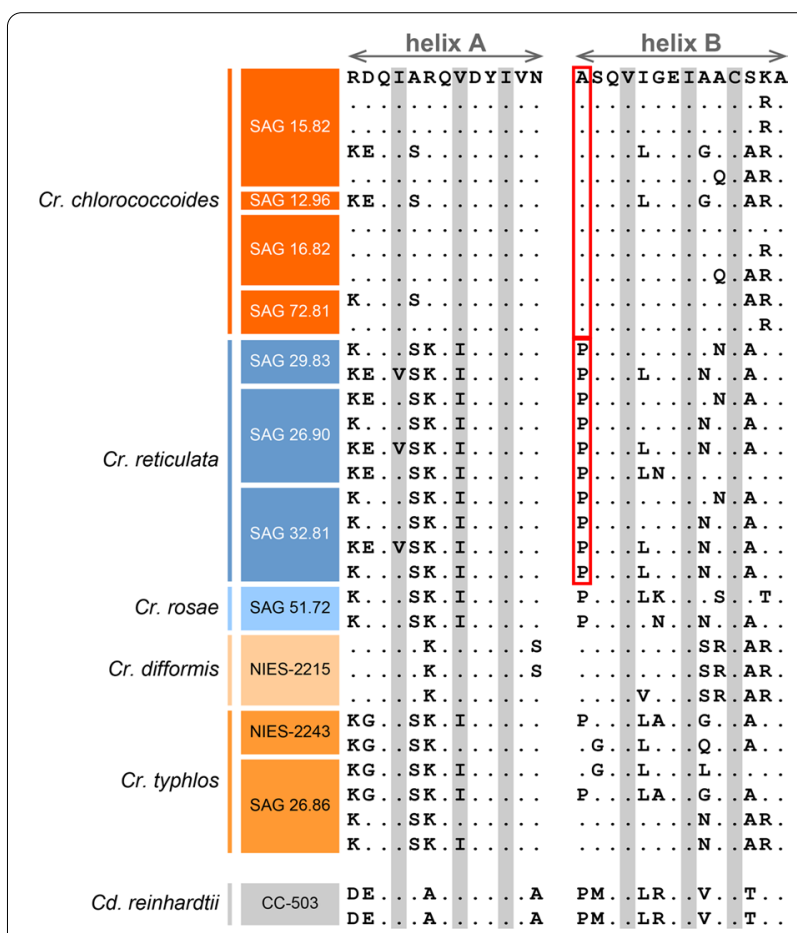

Fig. 4 Amino acid alignment of helices A and B of RBCS homologs from the Reticulata group and Chlamydomonas reinhardtii (Table 1). Dot means that amino acid in the position is the same as that in the top sequence. Eliminated amino acids by less than 15\% exposure ratio are grayed-out. The first position of helix $B$ was alanine in all of the RBCS sequences from Chloromonas chlorococcoides, while proline in that from C. reticulata (surrounded by the red solid-line frames) consider that the loss of pyrenoids may be based on the total hydrophobicity of 21 amino acids of helices A and B of RBCS within the Reticulata group (Fig. 3a). Thus, hydrophobicity of the other 20 amino acid positions may also contributes to presence or absence of pyrenoids in the Reticulata group. Although the pyrenoid-containing species C. typhlos has proline in the 131 amino acid position of two of six RBCS proteins (Fig. 4), total amino acid hydrophobicity is relatively high (Fig. 3a).

\section{Discussion}

In the present paper, we resolved possible correlation between the hydrophobicity of RBCS helices and presence/absence of pyrenoids in the Reticulata group of Chloromonas. This is possibly due to the unique fact that the Reticulata group shows presence and absence of pyrenoids within closely related species or even between sister species (Figs. 1 and 3). We also found that the hydrophobicity of the RBCS helices does not necessarily correspond to the presence or absence of a pyrenoid among the large lineages (strongly supported primary clades [14]) within Chlamydomonadales (Fig. 3b). It is thus clearly difficult to resolve the correlation between the RBCS amino acid sequences and presence/absence of pyrenoids across major lineages of chlorophytes and streptophytes [13].

The environmental conditions play an important role in pyrenoid presence/absence in some species (e.g. Volvulina steinii [30]). However, the Reticulata group of Chloromonas does not show variability in presence or absence of pyrenoids within a species when cultured under usual light/dark conditions [6, 16-18]. Thus, presence or absence of the pyrenoids in the Reticulata group is not directly affected by cultural or environmental conditions, but it is genetically determined. The present study clearly demonstrated part of such genetic differences in $r b c S$ genes between pyrenoid-containing and -lacking species.

\section{Conclusion}

Recent extensive studies demonstrated that various molecular factors are possible to contribute to interaction between Rubisco and other proteins to form pyrenoids [8-12]. Loss of pyrenoids might have occurred many times in the distant past independently during the evolution of photosynthetic eukaryotes. Thus, it seems difficult to discuss the critical factor that might have directly caused the initial evolution of pyrenoid loss. Based on the use of the Reticulata group of Chloromonas, however, we here suggested that the hydrophobicity of the helices A and $B$ of RBCS is a possible factor that might have caused the initial loss of pyrenoid during speciation between the pyrenoid-containing and -lacking species (Fig. 3a). 
Although the decrease in such hydrophobicity may be the major factor for evolutionary loss of pyrenoids in the Reticulata group, presence or absence of the EPYC-1-like protein is totally unknown in this group. RBCL amino acid substitutions may be related to the presence or absence of pyrenoids in Chloromonas [15]. Transformation protocols have not been established in Chloromonas. Further molecular genetic studies are needed to resolve actual molecular bases for evolutionary loss of pyrenoids in the Reticulata group.

\section{Methods}

\section{Phylogenetic analyses of 11 Chloromonas strains of the Reticulata group}

Molecular phylogenetic analyses were conducted based on Makino et al. [17] with additional sequences of nuclear internal transcribed spacer 2 (ITS-2) (Additional file 2: Table S1), using MrBayes 3.2.7 [31] for BI, RAxML-NG 0.9 [32] for ML method, and PAUP* 4.0b10 [33] for MP and NJ analyses. The combined 7109-bp data matrix for nuclear $18 \mathrm{~S}$ and $28 \mathrm{~S}$ ribosomal DNA, ATP synthase $\beta$-subunit (atpB), and P700 chlorophyll $a$-apoprotein A2 (psaB) and $p s a A$ genes, and ITS-2 sequences from the 14 operational taxonomic units (11 Chloromonas strains of the Reticulata group and three outgroup species) was analyzed and available from TreeBASE (https://www.treebase.org/treebaseweb/home.html; study ID: S26516). For concatenating the data matrices, our previous studies showed that robust discrepancies in phylogenetic relationships within the Chloromonadinia clade were not detected among $18 \mathrm{~S}$ rDNA, $a t p B$ and $p s a B$-based trees [22, 27]. We also here confirmed that there are no robust discrepancies (supported $>60 \%$ bootstrap values) among $28 \mathrm{~S}$ rDNA, $p s a A$ and ITS-2based trees in the Reticulata group (Additional file 1: Fig. S1). The outgroup species were selected according to the previous phylogenetic analyses [16, 17, 27]. The appropriate substitution models for partitioned analyses in $\mathrm{BI}$ and ML method were selected by the Bayesian information criterion in Modeltest-NG v0.1.6 [34] with "-T mrbayes" option. The applied substitution models were as follows: $\mathrm{K} 80+\mathrm{I}$ for $18 \mathrm{~S}$ ribosomal DNA, K80+G4 for $28 \mathrm{~S}$ ribosomal DNA and ITS-2, HKY+I for the 1st codon position of atpB, $p s a A$ and $p s a B, \mathrm{~F} 81+\mathrm{I}+\mathrm{G} 4$ for the 2nd codon position of $a t p B$, $p s a A$ and $p s a B$, and GTR+G4 for the 3rd codon position of $a t p B, p s a A$ and $p s a B$. BI was performed as in the previous study [17] with 1,000,000 generations of Markov chain Monte Carlo iterations and discarding the first 25\% as burn-in. In each analysis, the average standard deviation of split frequencies was below 0.01 , indicating convergence. For ML analysis, 10 randomized parsimony starting trees were generated. MP analysis was carried out based on random additions of 10 replicates from a heuristic search using the tree-bisection-reconnection branch-swapping algorithm. For NJ analysis, GTR $+\mathrm{I}+\mathrm{G}$ model was selected by the Bayesian information criterion in jModelTest 2.1 [35]. Bootstrap values [19] based on 1000 replications were calculated in ML, MP and NJ analyses.

\section{Cultures}

Eleven strains of five species in the Reticulata group [17] were obtained from the Culture Collection of Algae at Göttingen University (SAG; https://www.uni-goettingen .de/en/www.uni-goettingen.de/de/184982.html) and the Microbial Culture Collection at the National Institute for Environmental Studies (NIES; https://mcc.nies.go.jp/ index_en.html): Chloromonas reticulata strains SAG 29.83, SAG 26.90, and SAG 32.86; C. rosae strain SAG 51.72; C. chlorococcoides strains SAG 15.82, SAG 12.96, SAG 16.82, and SAG 72.81; C. typhlos strains NIES2243 and SAG 26.86; and C. difformis strain NIES-2215. Two strains of Crucicarteria (a strongly supported primary clade in the Chlamydomonadales [14]) were also obtained from NIES: Carteria cerasiformis strains NIES424 and NIES-425. The cells were cultured in screw-cap tubes $(18 \times 150 \mathrm{~mm})$ containing about $10 \mathrm{~mL}$ of AF- 6 medium [36, 37] at $20^{\circ} \mathrm{C}$ under $110-150 \mu$ mol photons $\mathrm{m}^{-2} \mathrm{~s}^{-1}$ light from fluorescent lamps with a 14-h light:10$\mathrm{h}$ dark photoperiod. In addition, the snow algal species Chloromonas krienitzii strain NIES-3753 and C. muramotoi strain NIES-4284 were obtained from NIES and grown at $5{ }^{\circ} \mathrm{C}$, as described previously [20].

\section{RNA extraction, library construction and sequencing}

Total RNA from 11 Chloromonas strains of the Reticulata group and two snow species of Chloromonas (Additional file 3: Table S2) was isolated with TRIzol Reagent (Thermo Fischer Scientific, Carlsbad, CA, USA), as described by Featherston et al. [38] using cultures grown during the light photoperiod. The RNA was then treated using a TURBO DNA-free Kit (Thermo Fischer Scientific) to exclude genome DNA contamination and measured using an Agilent 4200 TapeStation (Agilent Technologies, Santa Clara, CA, USA). Ribosomal RNA was removed with a NEBNext Poly(A) mRNA Magnetic Isolation Module (New England Biolabs, Beverly, MA, USA), and sequencing libraries were prepared with the NEBNext Ultra Directional RNA Library Prep Kit for Illumina (New England Biolabs). The cDNA library was assessed using an Agilent 4200 TapeStation and NEBNext Library Quant Kit for Illumina (New England Biolabs). After normalization, paired-end sequencing $(250 \mathrm{bp} \times 2)$ was performed using an Illumina MiSeq (Illumina, San Diego, CA, USA) with a MiSeq Reagent Kit v2 (500 cycles) (Illumina).

For the Carteria cerasiformis strains (Additional file 3: Table S2), total RNA was extracted from freeze-stocked 
cells using an RNeasy Mini Kit (QIAGEN, Venlo, the Netherlands) according to the manufacturer's instructions. To synthesize the library, $1 \mu \mathrm{g}$ of total RNA was treated as follows. The ribosomal RNA was removed using a Ribo-Zero rRNA Removal Kit (Plant Leaf) (Illumina) as per the manufacturer's protocol. Sequencing libraries were prepared using the NEBNext mRNA Library Prep Kit for Illumina (New England Biolabs) with the following modifications. First-strand synthesis was performed without fragmenting the mRNA. After second-strand synthesis, double-stranded cDNA was fragmented to an average length of $500 \mathrm{bp}$ using a Covaris S2 sonication system (Covaris, Woburn, CA, USA). Paired-end sequencing $(300 \mathrm{bp} \times 2)$ was then conducted using an Illumina MiSeq with a MiSeq Reagent Kit v3 (600 cycles).

\section{De novo assembly}

The number of paired-end reads sequenced using Illumina MiSeq was shown in Additional file 3: Table S2. For the Chloromonas species, sequence adapters and low-quality bases in the MiSeq reads were removed using Trimmomatic V0.38 [39]. Searching from both read ends, any base that had a quality value lower than 3 was removed. Sliding window trimming was performed with a 4-base window, and bases with quality scores under 15 were cut.

The processed reads of the Chloromonas strains were assembled de novo into contigs using Trinity V2.8.5 [40] (Additional file 3: Table S2). Using tblastn [41], the transcriptome libraries were searched for $r b c S$ cDNA sequences, with the RBCS amino acid sequence of Chlamydomonas reinhardtii [28] serving as the search database. From the cDNA library, multiple contigs that contained the almost complete coding sequence (CDS) of $r b c S$ were acquired (Additional file 2: Table S2).

The transcriptome reads of the two Carteria cerasiformis strains were filtered using CLC Genomics Workbench ver. 9.5 (QIAGEN) with following parameters: Phred quality score $>30$; ambiguous nucleotides $=0$; and removal of truncated reads less than 50 nucleotides in length. The filtered reads were assembled de novo using the CLC Genomics Workbench with the following parameters: automatic word size and bubble size; minimum contig length, $300 \mathrm{bp}$; correction of contig sequence by reads mapping; mismatch $\cos t=2$; indel $\operatorname{cost}=3$; length fraction $=0.7$; and similarity fraction $=0.9$. Using the assembled contigs, the $r b c S$ cDNA sequences were searched as described above (Additional file 3: Table S2).

\section{Cloning and sequencing}

Because almost all strains of the Reticulata group possessed several $r b c S$ paralogs (including partial CDS) in the de novo assembly, the cDNA sequences of the $r b c S$ genes were verified by Sanger sequencing of the RT-PCR products. The cDNA was reverse-transcribed from the total RNA used for paired-end sequencing by Illumina MiSeq as described above, with Superscript III Reverse Transcriptase (Thermo Fischer Scientific). Approximately full-length paralog sequences of $r b c S$ (covering CDS of helices A and B) were amplified by PCR with KOD FX Neo (Toyobo, Osaka, Japan) using newly designed primers based on our transcriptome data (Additional file 4: Table S3). The PCR products were cloned for sequencing using a Zero Blunt TOPO PCR Cloning Kit (pCR-Blunt II-TOPO Vector, Thermo Fischer Scientific) and TOPO TA Cloning Kit (pCR 4-TOPO Vector, Thermo Fischer Scientific). Then, 307 base pairs of the clones corresponding to positions 156-465 of the Chlamydomonas reinhardtii rbcS CDS (accession number XM_001702357) (with one amino acid deletion) were determined using a BigDye Terminator v3.1 Cycle Sequencing Kit (Applied Biosystems, Foster City, CA) and ABI Prism 3130 Genetic Analyzer (Applied Biosystems). To eliminate sequencing errors from the analysis, only identical sequences detected in at least two clones were used to calculate the hydrophobicity and phylogeny (Additional file 3: Table S2). The results by the Sanger sequencing partially conflicted with those of the assembled Illumina data, possibly due to the chimeric $r b c S$ CDS resulting from the assembly of short similar sequences. Thus, only sequences of cloned $r b c S$ were used in the present analyses (Additional file 3: Table S2).

\section{Phylogenetic analysis of $r b c S$ paralogs from 11 Chloromonas strains of the Reticulata group}

The $307 \mathrm{bp}$ of $r b c S$ cDNA from the 11 strains of the Reticulata group and the two snow species (outgroup) of the genus Chloromonas (Additional file 3: Table S2) were aligned with MAFFT V7.429 [42], and the phylogeny was analyzed with MEGA X [43]. ML analysis with 1000 bootstrap replications [19] was performed based on T92+G+I model selected by the Bayesian information criterion in MEGA X. The alignment is available at TreeBASE (https://www.treebase.org/treebase-web/home. html; study ID: S26516).

\section{Calculating the hydrophobicity of RBCS helices A and B}

Following a previous study [10], 27 amino acids corresponding to positions $68-80$ and 131-144 in the Chlamydomonas reinhardtii RBCS protein (including transit peptide; accession number XP_001702409) were regarded as helices $\mathrm{A}$ and $\mathrm{B}$, respectively. The hydrophobicity of the two helices for each RBCS paralog was calculated as the sum of the hydrophobicity of the amino acid residues forming the helices, excluding embedded 
amino acid residues (i.e., not exposed to the surface). The amino acid positions corresponding to the embedded residues were investigated using the GetArea [44] (http:// curie.utmb.edu/getarea.html); the three-dimensional (3D) structure Chlamydomonas reinhardtii RBCS [45] served as input. The exposure ratio was used to evaluate how "embedded" an amino acid was. The exposure ratio is the ratio of the side-chain surface area to the "random coil" value, i.e., the average solvent-accessible surface area of amino acid $\mathrm{X}$ in the tripeptide Gly-X-Gly in a set of 30 random conformations. Previous research regarded an amino acid with an exposure ratio below $15 \%$ as "embedded" [46]; hence, these residues were eliminated from the calculation of hydrophobicity of the RBCS helices. Consequently, we ignored six amino acids corresponding to positions $71,75,78,134,138$, and 141 in the Chlamydomonas reinhardtii $\mathrm{RBCS}$ protein (accession number XP_001702409) within the 27 amino acids constituting the RBCS A and B helices (Additional file 5: Fig. S2). The Kyte-Doolittle hydrophobicity scale [29] was used for the hydrophobicity analysis.

\section{RBCS sequences of other Chlamydomonadales species} The RBCS sequences of other species in nine strongly supported primary clades (i.e., Chlorogonia, Dunaliellinia, Hafniomonas, Moewusinia, Oogamochlamydinia, Phacotinia, Radicarteria, Reinhardtinia, and Stephanosphaerinia) and an "uncertain phylogenetic group" (Spermatozopsis similis) of Chlamydomonadales [14, 24] were extracted from published databases (Table 1). The sequences were manually checked, and those which were too short or possible cross-contamination were removed. The hydrophobicity of the RBCS helices was calculated as described above.

\section{Supplementary information}

Supplementary information accompanies this paper at https://doi. org/10.1186/s12862-020-01733-1.

Additional file 1: Fig. S1. Bayesian phylogenetic trees of the Reticulata group of the genus Chloromonas based on 285 ribosomal DNA (a), psaA (b) and ITS-2 (c) sequences that constitute the combined data matrix for species phylogeny (Fig. 1).

Additional file 2: Table S1. Taxa/strains used for the phylogenetic analyses of the Reticulata group (Fig. 1) and DDBJ/ENA/GenBank accession numbers.

Additional file 3: Table S2. Summary of de novo transcriptome of rbcS cDNA in 11 strains of the Reticulata group, two snow species of the genus Chloromonas (Cr.), and two strains of Carteria (Ca.).

Additional file 4: Table S3. Newly designed primers for rbcS of the Reticulata group in Chloromonas.

Additional file 5: Fig. S2. 3D structure of RBCS showing the exposed and embedded amino acids of helices $A$ and $B$.
Abbreviations

atpB: ATP synthase $\beta$-subunit; BI: Bayesian inference; CDS: Coding sequence; EPYC1: Essential pyrenoid component 1; ITS-2: Nuclear internal transcribed spacer 2; ML: Maximum likelihood; MP: Maximum parsimony; NJ: Neighborjoining; psaA: P700 chlorophyll a-apoprotein A1; psaB: P700 chlorophyll a-apoprotein A2; RBCL: Rubisco large subunit; RBCS: Rubisco small subunit; RT-PCR: Reverse transcription-polymerase chain reaction; SA clade: Snow algae clade

\section{Acknowledgements}

We thank Ms. Tomoyo Makino for her valuable suggestions to the present study.

\section{Authors' contributions}

RM and HN conceived this study. RM, SS, HYa, MK, YK, HYO and TM performed the analysis. RM and HN drafted a first version of this manuscript. All authors contributed to revision and editing of the manuscript. All authors read and approved the final manuscript.

\section{Funding}

HN and TM were supported by Grants-in-Aid for Scientific Research (Nos. $16 \mathrm{H} 02518$ and $17 \mathrm{H} 03707$, respectively) from the Ministry of Education, Culture, Sports, Science and Technology (MEXT)/Japan Society for the Promotion of Science (JSPS) KAKENHI (https://www.jsps.go.jp/english/e-grants/). HYo and YK were supported by Cooperative Research Grant of the Genome Research for BioResource (14A-26), NODAI Genome Research Center, Tokyo University of Agriculture. RM was supported by a grant from the Institute for Fermentation, Osaka (IFO), Japan (Y-2019-008). The funders had no role in study design, data collection and analysis, decision to publish, or preparation of the manuscript.

\section{Availability of data and materials}

All relevant data are within the manuscript and its additional files. All sequence data have been deposited to NCBI/GenBank/DDBJ under the accessions as follows; DRA: DRR231178-DRR231190, DRR228661-DRR228664; transcriptome assembly: ICPZ01000001-ICPZ01001618, ICPY01000001-ICPY01011944, ICQA01000001-ICQA01014335, ICQG01000001-ICQG01001076, ICPU01000001-ICPU01018312, ICQD01000001-ICQD01019608, ICQC01000001-ICQC01000652, ICQE01000001-ICQE01006092, ICQF01000001-ICQF01001138, ICPV01000001-ICPV01021145, ICQB01000001ICQB01000873, ICPW01000001-ICPW01001000, ICPX01000001-

ICPX01001228, ICQZ01000001-ICQZ01028017, ICRA01000001-ICRA01031094; mRNA: LC547865-LC547896.

\section{Ethics approval and consent to participate}

Not applicable.

\section{Consent for publication}

Not applicable.

\section{Competing interests}

The authors declare that they have no competing interests.

\section{Author details}

${ }^{1}$ Center for Environmental Biology and Ecosystem Studies, National Institute for Environmental Studies, Onogawa, Tsukuba, Ibaraki 305-8506, Japan.

${ }^{2}$ Faculty of Life and Environmental Sciences, University of Tsukuba, Tsukuba, Ibaraki 305-8572, Japan. ${ }^{3}$ Research Institute of Green Science and Technology, Shizuoka University, Shizuoka 422-8529, Japan. ${ }^{4}$ NODAl Genome Research Center, Tokyo University of Agriculture, Setagaya-ku, Tokyo 156-8502, Japan. ${ }^{5}$ Department of Bioscience, Tokyo University of Agriculture, Setagaya-ku, Tokyo 156-8502, Japan. ${ }^{6}$ Department of Tropical Medicine and Parasitology, Juntendo University, 2-1-1 Hongo, Bunkyo-ku, Tokyo 113-8421, Japan. 7 Department of Biological Sciences, Graduate School of Science, The University of Tokyo, 7-3-1 Hongo, Bunkyo-ku, Tokyo 113-0033, Japan.

Received: 28 October 2020 Accepted: 10 December 2020 Published online: 25 January 2021 


\section{References}

1. Griffiths DJ. The pyrenoid. Bot Rev. 1970;36:29-58. https://doi. org/10.1007/BF02859154

2. Badger MR, Andrews TJ, Whitney SM, Ludwig ML, Yellowlees DC, Leggat W, et al. The diversity and coevolution of Rubisco, plastids, pyrenoids and chloroplast-based $\mathrm{CO}_{2}$-concentrating mechanisms in algae. Can J Bot. 1998;76:1052-71. https://doi.org/10.1139/b98-074.

3. Raven JA. Inorganic carbon acquisition by eukaryotic algae: four current questions. Photosynth Res. 2010;106:123-34. https://doi.org/10.1007/ s11120-010-9563-7.

4. Villarreal JC, Renner SS. Hornwort pyrenoids carbon-concentrating structures evolved and were lost at least five times during the last 100 million years. Proc Natl Acad Sci USA. 2012;109:18873-8. https://doi.org/10.1073/ pnas.1213498109.

5. Spreitzer RJ, Salvucci ME. Rubisco: structure, regulatory interactions, and possibilities for a better enzyme. Annu Rev Plant Biol. 2002;53:449-75. https://doi.org/10.1146/annurev.arplant.53.100301.135233.

6. Morita E, Abe T, Tsuzuki M, Fujiwara S, Sato N, Hirata A, et al. Role of pyrenoids in the $\mathrm{CO}_{2}$-concentrating mechanism: comparative morphology physiology and molecular phylogenetic analysis of closely related strains of Chlamydomonas and Chloromonas (Volvocales). Planta. 1999;208:36572. https://doi.org/10.1007/s004250050571.

7. Raven JA, Edwards D. Physiological evolution of lower embryophytes: Adaptations to the terrestrial environment. In: Hemsley AR, Poole I, editors. The evolution of plant physiology. From whole plants to ecosystems. London: Elsevier; 2004. pp. 17-41. https://doi.org/10.1016/B978-01233 9552-8/50003-2.

8. Mackinder LCM, Meyer MT, Mettler-Altmann T, Chen VK, Mitchell MC, Caspari $\mathrm{O}$, et al. A repeat protein links Rubisco to form the eukaryotic carbonconcentrating organelle. Proc Natl Acad Sci USA. 2016;113:5958-63. https ://doi.org/10.1073/pnas.1522866113.

9. Itakura AK, Chan KX, Atkinson N, Pallesen L, Wang L, Reeves G, et al. A Rubisco-binding protein is required for normal pyrenoid number and starch sheath morphology in Chlamydomonas reinhardtii. Proc Natl Acad Sci USA. 2019:116:18445-54. https://doi.org/10.1073/pnas.1904587116.

10. Meyer MT, Genkov T, Skepper JN, Jouhet J, Mitchell MC, Spreitzer RJ, et al. Rubisco small-subunit a-helices control pyrenoid formation in Chlamydomonas. Proc Natl Acad Sci USA. 2012;109:19474-9. https://doi. org/10.1073/pnas.1210993109.

11. Wunder T, Cheng SLH, Lai SK, Li HY, Mueller-Cajar O. The phase separation underlying the pyrenoid-based microalgal Rubisco supercharger. Nat Commun. 2018:9:5076. https://doi.org/10.1038/s41467-018-07624-w.

12. Atkinson N, Velanis CN, Wunder T, Clarke DJ, Mueller-Cajar O, McCormick AJ. The pyrenoidal linker protein EPYC1 phase separates with hybrid Arabidopsis-Chlamydomonas Rubisco through interactions with the algal Rubisco small subunit. J Exp Bot. 2019;70:5271-85. https://doi. org/10.1093/jxb/erz275.

13. Goudet MMM, Orr DJ, Melkonian M, Müller KH, Meyer MT, Carmo-Silva E, Griffiths H. Rubisco and carbon-concentrating mechanism coevolution across chlorophyte and streptophyte green algae. New Phytol. 2020:227:810-23. https://doi.org/10.1111/nph.16577.

14. Nakada T, Misawa K, Nozaki H. Molecular systematics of Volvocales (Chlorophyceae Chlorophyta) based on exhaustive 18S rRNA phylogenetic analyses. Mol Phylogenet Evol. 2008;48:281-91. https://doi.org/10.1016/j. ympev.2008.03.016

15. Nozaki H, Onishi K, Morita E. Differences in pyrenoid morphology are correlated with differences in the $\mathrm{rbcL}$ genes of members of the Chloromonas lineage (Volvocales Chlorophyceae). J Mol Evol. 2002;55:414-30. https://doi.org/10.1007/s00239-002-2338-9.

16. Matsuzaki R, Hara Y, Nozaki H. A taxonomic revision of Chloromonas reticulata (Volvocales Chlorophyceae) the type species of the genus Chloromonas based on multigene phylogeny and comparative light and electron microscopy. Phycologia. 2012;51:74-85. https://doi. org/10.2216/11-18.1.

17. Makino T, Matsuzaki R, Suzuki S, Yamaguchi H, Kawachi M, Nozaki H. Taxonomic re-examination of two NIES strains of "Chlamydomonas" within the Reticulata group of the genus Chloromonas (Volvocales Chlorophyceae). Microb Resour Syst. 2019;35:13-23.

18. Morita E, Abe T, Tsuzuki M, Fujiwara S, Sato N, Hirata A, et al. Presence of the $\mathrm{CO}_{2}$-concentrating mechanism in some species of the pyrenoid-less free-living algal genus Chloromonas (Volvocales Chlorophyta). Planta. 1998;204:269-76. https://doi.org/10.1007/s004250050256.

19. Felsenstein J. Confidence limits on phylogenies: an approach using the bootstrap. Evolution. 1985;39:783-91. https://doi. org/10.1111/j.1558-5646.1985.tb00420.x

20. Teshima KM, Innan $H$. The effect of gene conversion on the divergence between duplicated genes. Genetics. 2004;166:1533-60. https://doi. org/10.1534/genetics.166.3.1553.

21. Matsuzaki R, Nozaki H, Takeuchi N, Hara Y, Kawachi M. Taxonomic re-examination of "Chloromonas nivalis (Volvocales Chlorophyceae) zygotes" from Japan and description of C. muramotoi sp. nov. PLoS ONE. 2019;14:e0210986. https://doi.org/10.1371/journal.pone.0210986.

22. Matsuzaki R, Kawai-Toyooka H, Haram Y, Nozaki H. Revisiting the taxonomic significance of aplanozygote morphologies of two cosmopolitan snow species of the genus Chloromonas (Volvocales Chlorophyceae). Phycologia. 2015;54:491-502. https://doi.org/10.2216/15-33.1.

23. Ettl H. Chlorophyta I. Phytomonadina. In: Ettl H, Gerloff J, Heynig H, Mollenhauer D, editors. Süßwasserflora von Mitteleuropa 9. Stuttgart: G. Fischer Verlag; 1983. p. 1-807. German.

24. Lemieux C, Vincent AT, Labarre A, Otis C, Turmel M. Chloroplast phylogenomic analysis of chlorophyte green algae identifies a novel lineage sister to the Sphaeropleales (Chlorophyceae). BMC Evol Biol. 2015;15:264. https://doi.org/10.1186/s12862-015-0544-5.

25. Nozaki H, Aizawa K, Watanabe MM. A taxonomic study of four species of Carteria (Volvocales Chlorophyta) with cruciate anterior papillae based on cultured material. Phycologia. 1994;33:239-47. https://doi.org/10.2216/ i0031-8884-33-4-239.1.

26. Hoham RW, Bonome TA, Martin CW, Leebens-Mack JH. A combined $18 \mathrm{~S}$ rDNA and rbcL phylogenetic analysis of Chloromonas and Chlamydomonas (Chlorophyceae, Volvocales) emphasizing snow and other cold-temperature habitats. J Phycol. 2002;38:1051-64. https://doi. org/10.1046/j.1529-8817.2002.t01-1-01227.x.

27. Matsuzaki R, Nakada T, Hara Y, Nozaki H. Description of Chloromonas kasaiae sp. nov. (Volvocales, Chlorophyceae), based on comparative electron microscopy and molecular data. Phycologia. 2013;52:239-245. https://doi.org/10.2216/12-083.1.

28. Spreitzer RJ. Role of the small subunit in ribulose-1,5-bisphosphate carboxylase/oxygenase. Arch Biochem Biophys. 2003;414:141-9. https:// doi.org/10.1016/S0003-9861(03)00171-1.

29. Kyte J, Doolittle RF. A simple method for displaying the hydropathic character of a protein. J Mol Biol. 1982;157:105-32. https://doi. org/10.1016/0022-2836(82)90515-0.

30. Nozaki H, Hara Y, Kasaki H. Light and electron microscopy of pyrenoids and species delimitation in Volvulina (Chlorophyta, Volvocaceae). J Phycol. 1987;23:359-436

31. Lonquist FM, Teslenko P, van der Mark DL, Ayres A, Darling S, Höhna B, et al. MrBayes 3.2: efficient Bayesian phylogenetic inference and model choice across a large model space. Syst Biol. 2012;61:539-542. https://doi. org/10.1093/sysbio/sys029.

32. Kozlov AM, Darriba D, Flouri T, Morel B, Stamatakis A. RAxML-NG: a fast, scalable and user-friendly tool for maximum likelihood phylogenetic inference. Bioinformatics. 2019;35:4453-5. https://doi.org/10.1093/bioin formatics/btz305.

33. Swofford DL. PAUP*: phylogenetic Analysis Using Parsimony (* and other methods) [CD-ROM]. Version 4.0b10. Sinauer: Sunderland, MA. 2002.

34. Darriba D, Posada D, Kozlov AM, Stamatakis A, Morel B, Flouri T. ModelTest-NG: a new and scalable tool for the selection of DNA and protein evolutionary models. Mol Biol Evol. 2020;37:291-4. https://doi. org/10.1093/molbev/msz189.

35. Posada D. jModelTest: phylogenetic model averaging. Mol Biol Evol. 2008;25:1253-6. https://doi.org/10.1093/molbev/msn083.

36. Kato S. Laboratory culture and morphology of Colacium vesiculosum Ehrb. (Euglenophyceae). Jpn J Phycol. 1982;30:63-7 (Japanese with English abstract).

37. Kawachi M, Ishimoto M, Mori F, Yumoto K, Sato M, Noel M-H. MCC-NIES list of strains 9th Edition [Internet]. Tsukuba: Microbial Culture Collection at National Institute for Environmental Studies; 2013 [cited 2019 March 14]. Available from: http://mcc.nies.go.jp/download/list9th_e.pdf.

38. Featherston J, Arakaki Y, Hanschen ER, Ferris PJ, Michod RE, Olson BJSC, et al. The 4-celled Tetrabaena socialis nuclear genome reveals the essential components for genetic control of cell number at the origin of 
multicellularity in the volvocine lineage. Mol Biol Evol. 2018;35:855-70 https://doi.org/10.1093/molbev/msx332.

39. Bolger AM, Lohse M, Usadel B. Trimmomatic: a flexible trimmer for Illumina sequence data. Bioinformatics. 2014;30:2114-20. https://doi. org/10.1093/bioinformatics/btu170.

40. Grabherr MG, Haas BJ, Yassour M, Levin JZ, Thompson DA, Amit I, et al. Trinity: reconstructing a full-length transcriptome without a genome from RNA-Seq data. Nat Biotechnol. 2011;29:644-52. https://doi. org/10.1038/nbt.1883.

41. Altschul SF, Gish W, Miller W. Myers EW, Lipman DJ. Basic local alignment search tool. J Mol Biol. 1990;215:403-10. https://doi.org/10.1016/S0022 -2836(05)80360-2.

42. Katoh K, Standley DM. MAFFT multiple sequence alignment software version 7: improvements in performance and usability. Mol Biol Evol. 2013;30:772-80. https://doi.org/10.1093/molbev/mst010.

43. Kumar S, Stecher G, Li M, Knyaz C, Tamura K. MEGA X: molecular evolutionary genetics analysis across computing platforms. Mol Biol Evol. 2018;35:1547-9. https://doi.org/10.1093/molbev/msy096.

44. Fraczkiewicz R, Braun W. Exact and efficient analytical calculation of the accessible surface areas and their gradients for macromolecules. J Comput Chem. 1998;19:319-33. https://doi.org/10.1002/(SICI)1096987X(199802)19:3\%3c319::AID-JCC6\%3e3.0.CO;2-W.

45. Taylor TC, Backlund A, Bjorhall K, Spreitzer RJ, Andersson I. First crystal structure of Rubisco from a green alga Chlamydomonas reinhardtii. J Biol Chem. 2001;276:48159-64. https://doi.org/10.1074/jbc.M107765200.
46. Yuan Z, Burrage K, Mattick JS. Prediction of protein solvent accessibility using support vector machines. Proteins. 2002;48:566-70. https://doi. org/10.1002/prot.10176.

47. Maddison WP, Maddison DR. Mesquite: a modular system for evolutionary analysis. Version 3.6 [software]. 2018 [cited 2019 March 13]. Available from: http://www.mesquiteproject.org.

48. Carpenter EJ, Matasci N, Ayyampalayam S, Wu S, Sun J, Yu J, et al. Access to RNA-sequencing data from 1,173 plant species: the 1000 plant transcriptomes initiative (1KP). GigaScience. 2019;8:1-7. https://doi. org/10.1093/gigascience/giz126.

49. Nakada T, Shinkawa H, Ito T, Tomita M. Recharacterization of Chlamydomonas reinhardtii and its relatives with new isolates from Japan. J Plant Res. 2010;123:67-78. https://doi.org/10.1007/s10265-009-0266-0.

50. Kawasaki Y, Nakada T, Tomita M. Taxonomic revision of oil-producing green algae, Chlorococcum oleofaciens (Volvocales, Chlorophyceae), and its relatives. J Phycol. 2015;51:1000-16. https://doi.org/10.1111/jpy.12343.

\section{Publisher's Note}

Springer Nature remains neutral with regard to jurisdictional claims in published maps and institutional affiliations.
Ready to submit your research? Choose BMC and benefit from:

- fast, convenient online submission

- thorough peer review by experienced researchers in your field

- rapid publication on acceptance

- support for research data, including large and complex data types

- gold Open Access which fosters wider collaboration and increased citations

- maximum visibility for your research: over 100M website views per year

At BMC, research is always in progress.

Learn more biomedcentral.com/submissions 